\title{
Concept of Integrality in General Medicine
}

\author{
Jose Luis Turabian*
}

\section{Specialist in Family and Community Medicine, Health Center Santa Maria de Benquerencia, Regional Health Service of Castilla la Mancha (SESCAM), Spain}

\begin{abstract}
The word Integral means to integrate, to bring together; to have a comprehensive vision of the patient is to take into account the interrelationships of the different dimensions of a person and see the whole as greater than the sum of its parts, as well as the acceptance of integration, or the whole, as a fact. Integrality is one of the basic characteristics of family medicine. Family doctor should be an "integrator", as an artist who is able to combine opposing colours, forms that fight each other, dissonances of all kinds, to form a unit. From the pedagogical point of view, some theoretical dimensions of Integrality in general medicine can be described: 1.-Provision of integrated and accessible services (Family physicians are responsible for serving a large majority of personal care needs); 2.-Comprehensive health services (Family/general health services include promotion of health, prevention of morbidity, curative care and terminal care); 3.-Comprehensive care (Biopsychosocial approach); 4.-Comprehensive understanding (Observer is an integral part of what he is observing; qualitative and quantitative); and 5.-Interactive Integrality (Reciprocal feedback; multiple perspectives). In family medicine, we need to know that "dividing an elephant in half does not produce two small elephants". This integrated approach, in general practice/family medicine is an increasingly needed to achieve a better level of health and affordable costs.
\end{abstract}

Keywords

Family practice, General practice, Integrative medicine, Integrated health care system, Systems integration

"The artist must train not only his eye but also his soul".

\section{Wassily Kandinsky}

Integral: The word means to integrate, to bring together, to join, to link, to embrace- Not in the sense of uniformity, but in the sense of unity-in-diversity. Integrality reflects the uniqueness and unity of human beings and their environment. To have a comprehensive vision of the patient is to take into account the interrelationships of the different dimensions of a person and see the whole as greater than the sum of its parts, as well as the acceptance of integration, or the whole, as a fact [1]. Figure 1 shows a first almost intuitive vision of the parts that are added to the integral approach of the patient in family medicine.

The concept of integrality refers us to the general theory of systems [2,3]. In its essence, system thinking is oriented to see how things are connected to each other within a certain notion of a complete entity. The general theory of systems applied to family medicine suggests that the elements of an organized group (for example the members of a family, the members of a group or community, etc.) are related to each other in such a way that the influence on one of the elements necessarily means influencing all others.

The family and the community are more than a group of individuals, because inside there is a set of stable patterns of interaction that determine the behavior of the individuals that compose it. Conceiving the family/community as a system helps to understand individual symptoms that may have a function within group dynamics. Thus, the persistence of the symptoms in an individual can indicate a difficulty on the part of his system (the family, etc.) to adapt to a certain situation of change or to solve a determined conflict.

The structure of the systems is defined by the way in which the elements of a system are interconnected or

${ }^{*}$ Corresponding author: Dr. Jose Luis Turabian, Specialist in Family and Community Medicine, Health Center Santa Maria de Benquerencia, Regional Health Service of Castilla la Mancha (SESCAM), Toledo, Spain, E-mail: jturabianf@ hotmail.com

Accepted: July 26, 2018; Published online: July 28, 2018

Citation: Turabian JL (2018) Concept of Integrality in General Medicine. Arch Fam Med Gen Pract 3(1):54-57

Copyright: (c) 2018 Turabian JL. This is an open-access article distributed under the terms of the Creative Commons Attribution License, which permits unrestricted use, distribution, and reproduction in any medium, provided the original author and source are credited. 


\section{FIGURE 1. CONCEPT OF INTEGRALITY IN GENERAL MEDICINE}

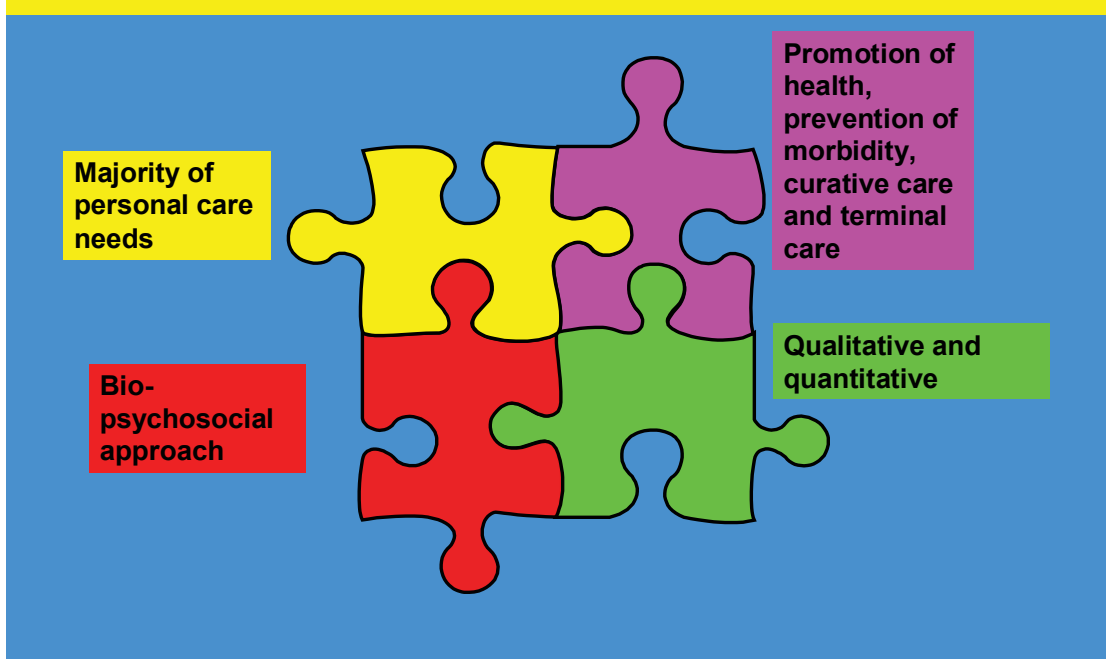

Figure 1: Concept of integrality in general medicine.

Table 1: Theoretical dimensions of integrality in general medicine.

\section{Theoretical dimensions of integrality}

1. Provision of integrated and accessible services

2. Comprehensive health services

3. Comprehensive care

4. Comprehensive understanding

5. Interactive Integrality

\section{Concept}

Physicians are responsible for serving a large majority of personal care needs Health services include promotion of health, prevention of morbidity, curative care and terminal care

Bio-psychosocial approach

Observer is an integral part of what he is observing; qualitative and quantitative Reciprocal feedback; multiple perspectives

Source: Self made.

communicated. Communication is the foundation of all system life. If any exchange of oral or written signs is suppressed in a social group, the group as such will cease to exist. The communication between the elements of a system satisfies two needs: A primary desire to inform, insofar as it is directed to human reason or intelligence; and to persuade, by addressing affectivity, feelings and emotions [4].

Communication is the authentic vehicle of any system, including social system, but it is not a simple and linear process, but complex and circular. The General Systems Theory studies the interrelations between the components of a system and between the systems and the supra-system; therefore, it gives special importance to communication and to how the components of the systems interact; without communication, the units would remain isolated, the system would not exist [5-7].

Starting from the different parts that the family doctor must intuitively put together when attending to the patient (Figure 1), we can, from the pedagogical point of view, refine something the theoretical dimensions of Integrality in general medicine. Table 1 describes this theoretical conceptualization, using for its design the pa- rameters of availability, accessibility, quality and adaptability of the health system and the family doctor. In any case, the concepts presented here are based on reflective experience and subsequent conceptualization and may differ in certain nuances with respect to those presented by other authors. In addition, the dimensions presented may overlap each other. They represent, therefore, a vision and personal hypothesis, subject to its acceptance or later refutation.

1.- Integrality is the ability to solve most of the health problems of the population served. It is considered that the resolutivity of family medicine is around $90 \%$. So, we could define general medicine as the provision of "integrated" and accessible services by physicians who are responsible for serving a large majority of personal care needs, developing an ongoing partnership with patients and working within the family and the community. Integrality is one of the four basic characteristics of family medicine, together with accessibility, coordination, and continuity or longitudinality $[8,9]$.

Comprehensive care at the level of general medicine requires changes in the organizational structure of the usual health system: Instead of differentiation by special- 
ization, the general practitioner incorporates many technical functions within a single role. General practitioner is who can take care of most of the problems presented by the patient, and when referred to another specialist of a certain medical area, he continues to remain in close contact with the patient and the other doctors. In addition, the family doctor attends from birth to death. Family doctors are more accessible than other specialists and thus basically work in the community, not in hospitals [10].

2.- General medicine provides comprehensive health services, which include the promotion of health, prevention of morbidity, curative care and terminal care, integrated and coordinated according to the needs of each patient. Integrality is inserted as a fundamental guide in the Health System and is understood as a set of notions related to greater multi-professional assistance. For this, the actions of promotion, prevention, protection and recovery of health are prioritized [11].

3.- Comprehensive care in general medicine must address the biological, psychological and social aspects of each patient. The general practitioner has a high clinical base and scientific solvency that allows him to be a polyvalent and resolutive doctor, analysing the human being under the bio-psychosocial approach, and being aware that he has feelings, desires, afflictions and rationalities. As a principle of the Health System, integrality implies the understanding of the patient, inserted in different contexts, from the biopsychosocial, cultural and spiritual dimensions, and focused on individual needs [12-15].

Several population groups raise issues that demand comprehensiveness as a basis for their health assistance strategies. For example, it is possible to mention the mental health and health of indigenous populations. However, probably one of the issues that should have a major breakthrough in terms of integrality is women's health. Regarding assistance to women, comprehensive care is based on three aspects: Public policies that help the demands of the female population; the gender-oriented organization of the medical service; and the gender-oriented practices of health professionals [16-18].

4.- In the practice of family medicine, integrality implies the understanding that the observer is an integral part of what he is observing. Thus, the focus is on collaboration (including our patients), the co-evolution of knowledge and health patterns, and as well as on unitary thinking that does not reject objective analysis, but recognizes its limits, and incorporates the subjective.

5.- Interactive Integrality: Means having the perception and consideration of communicative relationships at multiple levels, each of which maintains reciprocal feedback with the rest, and each of them produces mul- tiple perspectives for the observers; It is an organized communication.

The object of treatment in family medicine is basically to achieve "integrations". Like the artist who is able to combine opposing colours, forms that fight each other, dissonances of all kinds, to form a unit, or the great theoretician when he gathers surprising and inconsistent facts so that we can realize their mutual interdependence; and we can say the same about the great statesman, the philosopher, the inventor ..., the family doctor is also an 'integrator'. All these people described above have in common that they are integrators: People capable of gathering separate and even opposed elements in a unit.

This supposes a key and differentiating element of the treatment in general medicine: An integrating therapeutic capacity that acts as much looking for the integration inside the person, as in its external world, and that both interacts. The therapeutic effort is directed to the healing of the divisions, dichotomies or internal and external fragmentations of the individual in their context; To achieve healing is to make the person more unified, more integrated, making conscious and using their relationships, resources and contexts [8].

Integrality in general medicine also means that family doctor is committed to the total person rather than to a particular body of knowledge, group of diseases or a special technique. That commitment extends in two ways: First, it is not limited by the type of health problems; the family doctor is available for any health problem in a person of any sex and age; its practice is not even limited to what is strictly defined as a health problem: The patient defines the problem; This means that a family doctor can never say, "I'm sorry, but your discomfort or illness is not in my field". Any health problem of our patients is our field; although we can refer the patient for specialized treatment, we are responsible for the initial assessment and coordination of care. Second, the commitment does not have a definite endpoint; it does not end with the cure of a disease, the completion of a course of treatment or the incurability of a disease; in many cases the commitment is established while the person is healthy, before they have developed any problem, that is, family medicine is defined in terms of relationships, which makes it unique in the main fields of clinical medicine [19].

Thus, we can say that patients treated in general medicine are "integral clinical cases" $[20,21]$ when their information includes:

- Bio-psycho-social data

- Quantitative and qualitative data

- Experience of the disease by the patient and its context 
- Various actors or protagonists: Patient, family, specialists, relatives, community, etc.

- History biographical: Projects, expectations, etc.

- Relation doctor-patient-family-context

- Evaluation of family aspects (genogram, list of problems, family life cycle ...) and community (resources, strengths and weaknesses, relationships ...), in diagnosis and treatment

We can have the idea that the challenge of health services is to treat the pathologies one by one, but the problem is that users do not have only one disease, but several at a time and the health problems of people are not the same as their illnesses, which makes an environment of great complexity [22].

In family medicine, we need to know that "dividing an elephant in half does not produce two small elephants" $[23,24]$. Human systems are infinitely complex, we can not understand everything (or divide it into parts); we have cognitive limitations. The division of disciplines makes it impossible to take the integral whole. To maintain this systemic approach, a general practitioner is increasingly needed. It has been shown that a greater use of specialists is not associated with better health and increases costs [11]. It is best to keep the patient in primary care whenever possible, where he or she can be understood and treated integrally.

\section{References}

1. Wilber K (2001) A Theory of Everything. An integral vision for business, politics, science and spirituality. Shambhala, Boston.

2. Von Bertalanffy L (1975) General System Theory. Foundations, development, applications. George Braziller, New York, USA.

3. Rambihar VS, Rambihar V, Rambihar S (2014) Age of complexity. Can Fam Physician 60: 321-323.

4. Turabian JL (2017) Stories notebook about the fundamental concepts in family medicine: Comprehensiveness and integrality, the fable of the tree and the grass. J Gen Pract (Los Angel) 5: 284.

5. Bollini MT (1994) La teoría general de los sistemas y el origen olvidado de una psicología sistémica. Lumen, Buenos Aires.

6. Capra F (1996) The web of life. A new scientific understanding of living systems. Anchor Books, New York, USA.

7. Peters DH (2014) The application of systems thinking in health: Why use systems thinking? Health Research Policy and Systems 12: 51.

8. Turabian JL (2017) How do family doctors cure, Resolve, and treat? J Gen Pract (Los Angel) 5: e118.

9. Turabian JL (1995) Cuadernos de Medicina de Familia y Comunitaria. Una introducción a los principios de Medicina de Familia. [Family and Community Medicine notebooks. An Introduction to the Principles of Family Medicine ]. Díaz de Santos, Madrid.

10. Gunderman R (2016) Hospitalists and the decline of comprehensive care. N Engl J Med 375: 1011-1013.

11. Starfield B (2009) Toward international primary care reform. CMAJ 180: 1091-1092.

12. Heath I (1995) The mystery of general practice. Nuffield Trust.

13. Turabian JL, Perez-Franco B (2016) The family doctors: Images and metaphors of the family doctor to learn family medicine. Nova Publishers, New York.

14. Hayes C, Naylor R, Egger G (2012) Understanding chronic pain in a lifestyle context: The Emergence of a Whole-Person Approach. Am J Lifestyle Med 6: 421-428.

15. Turabian JL, Perez Franco B (2007) Big mysteries. Can you see the loch ness monster? The biopsychosocial model and community activities. Aten Primaria 39: 261-264.

16. Pinheiro TF, Couto MT (2013) Sexuality and reproduction: Discussing gender and integral care in Primary Health Care. Physis 23: 73-92.

17. Turabian JL (2017) Clinical competencies in the care of women: Intertextuality and transversality between gynecology and family medicine. Gynecol Obstet (Sunnyvale) 7: e121.

18. Turabian JL (2017) Is the meaning of symptoms the same in women and men? J Women's Health Care 6: 376.

19. Turabian JL, Pérez Franco B (2001) Actividades comunitarias en medicina de familia y atención primaria. [Community activities in family medicine and primary care]. Díaz de Santos, Madrid.

20. Turabian JL (2016) Clinical musical stories of family medicine. Editorial Académica Española, Saarbrücken, Deutschland/Germany.

21. Perez Franco B, Turabian JL (2003) Work experiences with "integrated" clinical cases for practice and training in general medicine. Aten Primaria 31: 400.

22. Bonn D (2001) Biocomplexity: Look at the whole, not the parts. Lancet 357: 288.

23. Turabian JL (2017) Fables of family medicine. A collection of fables that teach the Principles of Family Medicine. Editorial Académica Española, Saarbrücken, Deutschland/Germany.

24. Turabian JL (2017) A short collection of fables for learning the fundamental principles of family medicine: Chapter 1. Comprehensiveness, continuity, contextualization and family. Ann Fam Med Gen Pract 1: 32-39. 